\title{
The effect of creatine supplementation on seizure control in children under ketogenic diet: A pilot study
}

\author{
Serafeia Kalamitsou', Susan Masino², Evangelos Pavlou ${ }^{3}$, Maria Gogou ${ }^{4}$, Irene Katsanika ${ }^{5}$, Kyriaki Papadopoulou-Legbelou ${ }^{6}$, Aspasia $^{2}$ \\ Serdari $^{7}$, Martha Spilioti ${ }^{8}$ and Athanasios Evangeliou ${ }^{4 *}$ \\ ${ }^{1}$ Pediatric Intensive Care Unit, Hippokrateio General Hospital, Thessaloniki, Greece \\ ${ }^{2}$ Trinity College, Psychology/Neuroscience, Hartford, Connecticut, USA \\ ${ }^{3} 2^{\text {nd }}$ Pediatric Department, School of Medicine, Aristotle University of Thessaloniki, University General Hospital AHEPA, Thessaloniki, Greece \\ ${ }^{4} 4^{\text {th }}$ Pediatric Department, School of Medicine, Aristotle University of Thessaloniki, Papageorgiou General Hospital, Thessaloniki, Greece \\ ${ }^{5} 1^{\text {st }}$ Pediatric Department, School of Medicine, Hippokrateio General Hospital, Thessaloniki, Greece \\ ${ }^{6}$ Dietician Department, Papageorgiou General Hospital, Thessaloniki, Greece \\ ${ }^{7}$ Department of Child Psychiatry, School of Medicine, Demokritus University of Thrace, Alexandroupoli, Greece \\ ${ }^{8} 1^{\text {st }}$ Neurology Department, School of Medicine, Aristotle University of Thessaloniki, University General Hospital AHEPA, Thessaloniki, Greece
}

\begin{abstract}
Introduction: The ketogenic diet improves cell energy and mitochondrial function and supplemental creatine can similarly improve cell energy. Our aim is to investigate the role of creatine as an adjunctive therapy to the ketogenic diet.

Material and methods: A prospective study was carried out in 22 children with refractory epilepsy. All patients were initially on ketogenic diet and none was seizurefree, although 12 children had benefited.

Results: Creatine supplementation produced a complete cessation of seizures in 2 patients and a $70 \%$ to $90 \%$ reduction in seizure frequency was reported in additional five patients. Creatine was well-tolerated and did not change the level of ketosis.

Conclusions: Although these data involve a small cohort, the effects of creatine were uniformly positive or neutral. We suggest that creatine supplementation may increase the effectiveness of the ketogenic diet in seizure reduction, likely by increasing phosphocreatine and enhancing brain energy balance.
\end{abstract}

\section{Introduction}

Despite rapid progress in new antiepileptic drugs development the prevalence of drug resistant epilepsy has remained stable and is estimated at $30-40 \%$ of cases [1]. There is evidence that drug resistant epilepsy is characterized by disturbed brain energy balance accompanied by low brain phosphocreatine levels [2,3]. Under this view enhancing energy balance in these patients may improve clinical symptoms. In parallel, the antiepileptic effects of ketogenic diet could be attributed to increase in ATP and phosphocreatine levels and consequent improvement of promotion of energy balance within the Central Nervous System [4,5]. While ketogenic diet is effective in some cases, not all patients benefit from it; in most cases this differential response to the diet is not well understood. The key underlying anticonvulsant mechanisms of this diet therapy remain a subject of active research [6,7].

On the other hand, emerging clinical and experimental data in recent years suggest beneficial effects of creatine on hypoxic/ischemic injury in the developing brain, as well as on traumatic brain injury [8-11]. Additional evidence implies a potential role of creatine in the pathophysiology of refractory epilepsy $[12,13]$. It is also noteworthy that creatine and ketogenic diet share a common property which can provide a potential pathophysiological background for their anticonvulsant effects; both ketogenic diet and creatine contribute to the energy balance of the body by increasing the phosphocreatine/ creatine ratio [14-17]. Therefore, co- administration of creatine with ketogenic diet could help achieve better energy balance in patients with epilepsy by increasing phosphocreatine levels in the brain. From this perspective, ketogenic diet and creatine may act in a synergistic way and supplementary creatine may be a way to increase the "dose" of the diet. (Figure 1)

The aim of our study is to investigate in clinical practice the role of creatine supplementation as an adjunctive therapy to ketogenic diet. Our rationale was that increasing the phosphocreatine: creatine ( $\mathrm{PCr}: \mathrm{Cr}$ ) energy-store ratio - and thus increase energy production in the brain - could enhance the efficacy of the diet and increase its clinical benefits.

*Correspondence to: Athanasios Evangeliou, Pediatrics and Child Neurology, 4th Department of Pediatrics, Aristotle University of Thessaloniki, Papageorgiou Hospital, Thessaloniki, Greece, Tel. 00306948690924, E-mail: aeevange@auth.gr

Key words: creatine, refractory epilepsy, ketogenic diet, seizures, pediatric neurology

Received: January 09, 2019; Accepted: February 06, 2019; Published: February 08,2019 


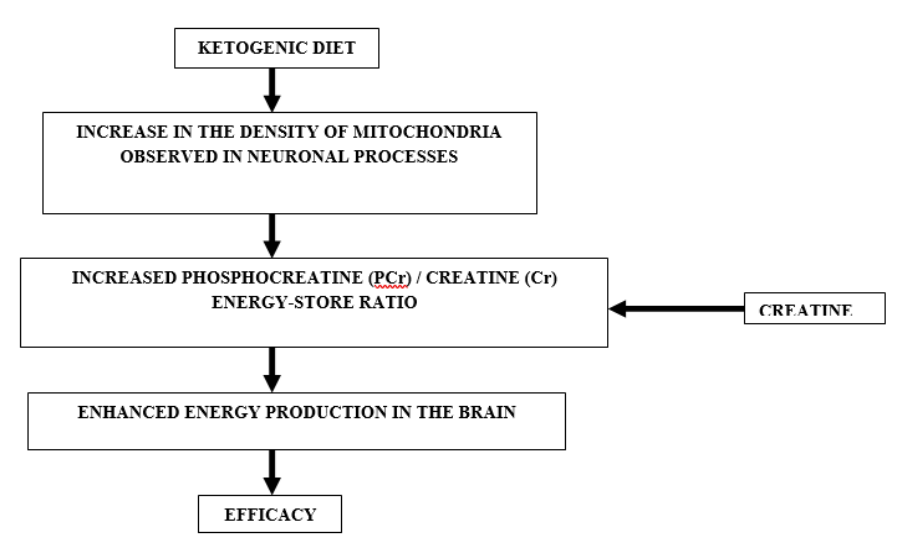

Figure 1. Proposal of synergistic action between creatine and ketogenic diet

\section{Material and methods}

We conducted an open-label trial approved by the Ethical Committee of the local University. All parents were asked to sign an informed consent form.

\section{Subjects}

Eligibility criteria of our study included: (i) children and adolescents with drug resistant epilepsy according to ILAE criteria [18], (ii) no diagnosis of inborn error of metabolism or GLUT-1 deficiency, (iii) administration of the 4:1 classical ketogenic diet for 8-24 months, (iv) no change in seizure frequency within past 3 months, (v) no change in antiepileptic drugs administration within past 3 months, (vi) normal kidney function.

\section{Procedures}

Before administration: Before adjuvant administration of creatine all patients underwent a 3-month observation period to ensure that no changes in seizure frequency, as well as in the administration schema of antiepileptic drugs occurred.

Seizure recording: Seizure documentation was determined by parents/caregivers-reported daily seizure logs kept for 1 month prior to ketogenic diet initiation (baseline seizure frequency) and continued after ketogenic diet initiation. Assessment of seizure improvement was achieved with the use of questionnaire filled in by the parents/ caregivers, which included number of seizures, seizure type, duration and intervals.

Creatine administration and monitoring: Creatine monohydrate from the same manufacturer was administered to all participants. Each patient was prescribed $0.4 \mathrm{~g} / \mathrm{kg}$ daily, per os, divided into two doses, and mixed into a beverage. Here we provided patients with a dose based on our prior experience with a clinical study using creatine ketones were measured daily throughout the study and all children underwent monthly renal ultrasounds. The first follow-up took place 1 month after creatine supplementation and thence forward every 3 months with electroencephalogram performance, as well as blood and urine analysis (kidney function tests included: levels of urea and creatine, calcium-to-creatine ratio in urine samples). Seizure frequency and antiepileptic medications were recorded on a daily basis. No changes to antiepileptic medication regimens were made during the study period.

\section{Definitions}

The main efficacy outcome measure was the proportion of responders to ketogenic diet +creatine therapy, which was defined as a reduction in seizure frequency of $>50 \%$.

Response to treatment was evaluated by the difference between the number of epileptic seizures occurring during ketogenic diet + creatine treatment and the number of epileptic seizures occurring in the period before starting treatment with creatine. Complete control was defined as no seizures occurring in the analysed period.

\section{Results}

From 42 patients initially recruited 22 finally met our eligibility criteria. (Figure 2) More specifically, the study sample included 13 boys and 9 girls, aged from 10 months to 8 years old. Patient diagnoses included epilepsy of genetic, infectious, traumatic or unknown origin and are summarized in Table 1. No specific cause was identified in children with Lennox-Gastaut and West syndrome, while diagnosis of Dravet syndrome was based on assessment of pathogenetic mutations in SCN1A gene. The duration of follow-up ranged from 3 to 12 months. Out of 22 patients on ketogenic diet, 12 had experienced a reduction in seizure frequency varying from $20 \%$ to $70 \%$ with the application of the ketogenic diet alone. None had experienced seizure freedom, while 10 children showed no improvement. (Table 2).

Upon the addition of creatine, 6 out of 22 children (27\%) responded to this nutritional intervention. One month after creatine supplementation 4 out of these 6 patients had a normal electroencephalogram, while the other 2 patients had a $90 \%$ reduction

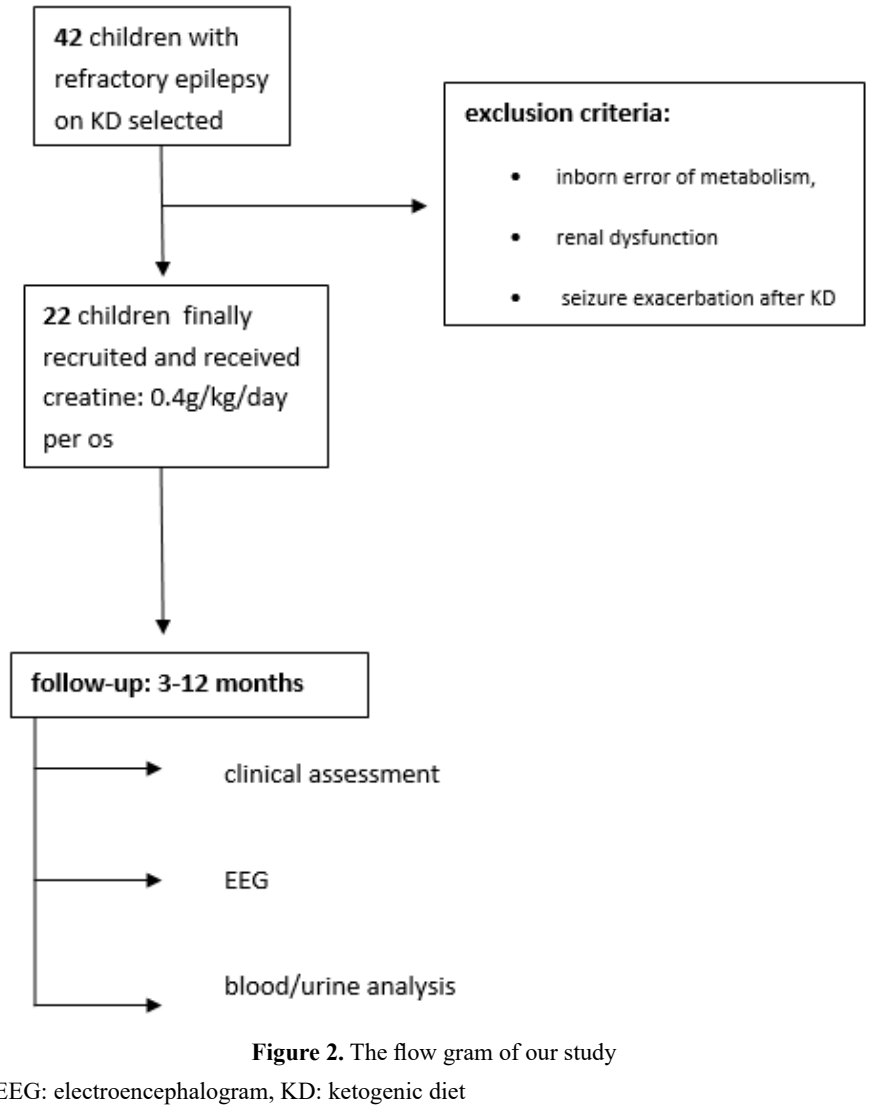


Table 1. Basic clinical traits of our sample before initiation of creatine administration

\begin{tabular}{|c|c|c|c|c|c|c|}
\hline Pat & Gender & Diagnosis & Seizure type & EEG & Seizures frequency & $\begin{array}{l}\text { Age at KD } \\
\text { initiation }\end{array}$ \\
\hline 1 & M & $\begin{array}{l}\text { Lennox-Gastaut } \\
\text { syndrome }\end{array}$ & Multiple & Generalized slow spike and wave discharges & $\begin{array}{l}>40 \text { abscences } / \mathrm{d}, 10-12 \text { atonic } / \mathrm{d} \\
>50 \text { myoclonic jerks } / \mathrm{d}\end{array}$ & $7 y$ \\
\hline 2 & M & West syndrome & Infantile spasms & Hypsarrhythmia & $>50$ per day & $15 \mathrm{~m}$ \\
\hline 3 & $\mathrm{M}$ & perinatal asphyxia & Infantile spasms & Hypsarrhythmia & $>60$ per day & $2 \mathrm{y}$ \\
\hline 4 & $\mathrm{~F}$ & West syndrome & Infantile spasms & Hypsarrhythmia & $>60$ per day & $10 \mathrm{~m}$ \\
\hline 5 & M & Encephalitis & Complex partial & Temporal spikes & 7 per week & $3 \mathrm{y}$ \\
\hline 6 & $\mathrm{~F}$ & Dravet syndrome & Myoclonic & Generalized, 4- to 6-Hz polyspike and wave discharges & $>30$ per day & $10 \mathrm{y}$ \\
\hline 7 & $\mathrm{~F}$ & Encephalitis & Secondarily generalized & Temporal spikes & 5 per week & $2 \mathrm{y}$ \\
\hline 8 & M & $\begin{array}{l}\text { Lennox-Gastaut } \\
\text { syndrome }\end{array}$ & Multiple & $\begin{array}{l}\text { Abnormally slow background and diffuse slow spike and slow } \\
\text { wave activity }\end{array}$ & $\begin{array}{c}\text { 1-2atonic/d, >50abscences } / \mathrm{d}, \\
>30 \text { myoclonic jerks } / \mathrm{d}, 1 \text { Grand Mal } / \mathrm{d}\end{array}$ & $4 \mathrm{y}$ \\
\hline 9 & M & $\begin{array}{l}\text { frontal lobe } \\
\text { epilepsy }\end{array}$ & Grand mal during sleep & $\begin{array}{l}\text { Generalized multiple spike and wave complexes, focal spike- } \\
\text { wave discharges over the left frontal region }\end{array}$ & 3 per week & $7 y$ \\
\hline 10 & $\mathrm{~F}$ & idiopathic epilepsy & $\begin{array}{l}\text { Grand mal during } \\
\text { awakening }\end{array}$ & Generalized multiple spike and wave complexes & 3 per week & $2 \mathrm{y}$ \\
\hline 11 & $\mathrm{~F}$ & $\begin{array}{l}\text { Lennox-Gastaut } \\
\text { syndrome }\end{array}$ & Multiple & Diffuse slow spike and wave complexes & $\begin{array}{l}>50 \text { tonic/d, 5-10atonic/ d, 2-3Grand } \\
\text { Mal/d }\end{array}$ & $4 \mathrm{y}$ \\
\hline 12 & M & $\begin{array}{l}\text { Lennox-Gastaut } \\
\text { syndrome }\end{array}$ & Multiple & Diffuse, slow and irregular spike and wave complexes & 20 tonic/d, 10 atonic/ d, 1 Grand Mal/d & $5 y$ \\
\hline 13 & $\mathrm{~F}$ & $\begin{array}{l}\text { Angelman } \\
\text { syndrome }\end{array}$ & Infantile spasms & Hypsarrhythmia & $>50$ per day & $5 \mathrm{y}$ \\
\hline 14 & M & perinatal asphyxia & Infantile spasms & Hypsarrhythmia & $>60$ per day & $1 \mathrm{y}$ \\
\hline 15 & M & DHII & Grand Mal & $\begin{array}{l}\text { Generalized polyspikes with frontocentral accentuation followed } \\
\text { by } 2.5 \mathrm{~Hz} \text { slow waves }\end{array}$ & 14 per week & 3 y \\
\hline 16 & M & PR & Atonic & Generalized spike and wave complexes & 8 per week & $4 \mathrm{y}$ \\
\hline 17 & M & idiopathic epilepsy & Grand mal & Generalized spike and wave complexes & 3 per week & $4 \mathrm{y}$ \\
\hline 18 & $\mathrm{~F}$ & Dravet syndrome & $\begin{array}{l}\text { Generalized Epilepsy with } \\
\text { febrile seizures plus }\end{array}$ & Generalized polyspikes & 4 per week & $8 \mathrm{y}$ \\
\hline 19 & $\mathrm{M}$ & idiopathic epilepsy & Partial complex & Theta wavesover the right temporal lobe & 9-10 per week & $5 y$ \\
\hline 20 & & idiopathic epilepsy & Partial complex & Occipital spikes & $10-14$ per week & $5 y$ \\
\hline 21 & $\mathrm{~F}$ & idiopathic epilepsy & Secondarily generalized & $\begin{array}{l}\text { Generalized multiple spike and wave complexes, Spikes over } \\
\text { the left temporal lobe }\end{array}$ & 2 per week & $7 y$ \\
\hline 22 & $\mathrm{~F}$ & perinatal asphyxia & $\begin{array}{l}\text { Generalized Epilepsy with } \\
\text { febrile seizures plus }\end{array}$ & Generalized multiple spike and wave complexes & 8 per week & $3 \mathrm{y}$ \\
\hline
\end{tabular}

PR:psychomotor retardation in addition to the seizures, with no progress and no obvious reason despite the extensive diagnostic screening; DHII: Diffuse Hypoxic Ischemic Injury; M: male; F: female; EEG: electroencephalogram; y: years; m: months; d:days; KD: ketogenic diet

in the electroencephalographic epileptic activity. It should be noted that all these 6 children were patients who had already benefited from ketogenic diet and experienced further improvement with creatine supplementation. (Table 2, Figure 3)

More specifically, with regards to seizure improvement, 2 patients who had already achieved near-complete seizure reduction on the ketogenic diet experienced a complete cessation, while 2 patients who had experienced a decrease in seizures of $70 \%$ and $60 \%$ with the ketogenic diet had a further reduction in seizure frequency ( $90 \%$ both) after the supplementary administration of creatine. In 2 other patients' improvement with the creatine supplementation was smaller: ketogenic diet-induced seizure reduction was $70 \%$ and $50 \%$ before creatine supplementation and $80 \%$ and $70 \%$ after creatine, respectively.

On the other hand, patients who experienced no improvement of their seizures on the ketogenic diet did not achieve any improvement of their seizures with the addition of creatine. Table 2 summarizes the reduction in seizure frequency in each patient expressed as percentage, as well as the pattern of antiepileptic drugs withdrawal.

Additionally, according to reports from parents or caregivers, an improvement was noted with regards to behavior and cognitive functioning in patients with seizure reduction after creatine administration, particularly in the fields of concentration, learning

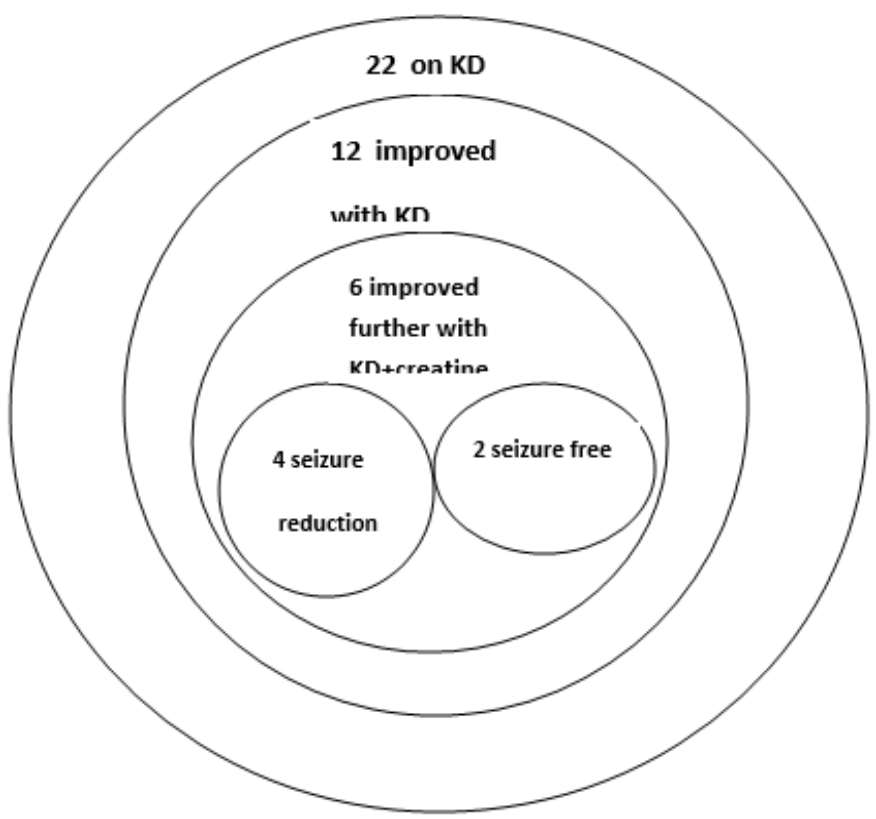

Figure 3. The effect of KD and creatine supplementation on epileptic activity in our cohort KD: ketogenic diet 
Table 2. The effect of creatine supplementation to KD on seizure control and the number of antiepileptic drugs used

\begin{tabular}{|c|c|c|c|c|c|c|c|c|}
\hline \multirow{3}{*}{ Pat } & \multirow{3}{*}{ Age at diet onset } & \multirow{3}{*}{$\begin{array}{c}\text { Follow-up in m } \\
\text { Only KD }\end{array}$} & \multirow{3}{*}{$\begin{array}{c}\text { Follow-up in m } \\
\text { KD +Creatine }\end{array}$} & \multirow{3}{*}{\begin{tabular}{|c|} 
Seizure reduction \\
Only KD (\%) \\
\end{tabular}} & \multirow{3}{*}{\begin{tabular}{|c|} 
Seizure \\
reduction \\
KD+Creatine (\%) \\
\end{tabular}} & \multirow{3}{*}{$\begin{array}{c}\text { Number of AED } \\
\text { Pre (KD) }\end{array}$} & \multirow{3}{*}{$\begin{array}{c}\text { Number of AED } \\
\text { (Only KD) }\end{array}$} & \multirow{2}{*}{$\begin{array}{r}\text { Number of AED } \\
\text { (KD+ creatine) }\end{array}$} \\
\hline & & & & & & & & \\
\hline & & & & & & & & \\
\hline 1 & $7 y$ & 24 & 12 & 60 & 100 & 3 & 2 & 1 \\
\hline 2 & $15 \mathrm{~m}$ & 24 & 6 & 50 & 100 & 2 & 1 & 1 \\
\hline 3 & $2 \mathrm{y}$ & 6 & 6 & 70 & 90 & 2 & 1 & 1 \\
\hline 4 & $10 \mathrm{~m}$ & 18 & 6 & 60 & 90 & 3 & 3 & 1 \\
\hline 5 & $3 y$ & 15 & 12 & 70 & 80 & 3 & 2 & 1 \\
\hline 6 & $10 \mathrm{y}$ & 7 & 7 & 50 & 70 & 4 & 3 & 3 \\
\hline 7 & $2 y$ & 9 & 6 & 70 & - & 3 & 2 & 2 \\
\hline 8 & $4 y$ & 9 & 6 & 60 & - & 3 & 3 & 3 \\
\hline 9 & $7 y$ & 12 & 12 & 50 & - & 4 & 3 & 3 \\
\hline 10 & $2 \mathrm{y}$ & 18 & 3 & 20 & - & 2 & 2 & 2 \\
\hline 11 & $4 y$ & 6 & 6 & 50 & - & 2 & 2 & 2 \\
\hline 12 & $5 y$ & 12 & 12 & 50 & - & 3 & 3 & 3 \\
\hline 13 & $5 y$ & 6 & 3 & - & - & 3 & 3 & 3 \\
\hline 14 & $1 \mathrm{y}$ & 4 & 4 & - & - & 3 & 3 & 3 \\
\hline 15 & $3 y$ & 5 & 4 & - & - & 3 & 3 & 3 \\
\hline 16 & $4 y$ & 8 & 4 & - & - & 3 & 3 & 3 \\
\hline 17 & $4 y$ & 4 & 6 & - & - & 2 & 2 & 2 \\
\hline 18 & $8 \mathrm{y}$ & 4 & 4 & - & - & 3 & 3 & 3 \\
\hline 19 & $5 \mathrm{y}$ & 7 & 6 & - & - & 2 & 2 & 2 \\
\hline 20 & $5 \mathrm{y}$ & 6 & 5 & - & - & 2 & 2 & 2 \\
\hline 21 & $7 y$ & 6 & 3 & - & - & 3 & 3 & 3 \\
\hline 22 & $3 y$ & 5 & 5 & - & - & 3 & 3 & 3 \\
\hline
\end{tabular}

KD: ketogenic diet; AED: antiepileptic drugs; y: years; m: months

PR:psychomotor retardation in addition to the seizures, with no progress and no obvious reason despite the extensive diagnostic screening; DHII: Diffuse Hypoxic Ischemic Injury; M: male; F: female, EEG: electroencephalogram; y: years; m: months; d:days; KD: ketogenic diet

ability and communication skills. All the above parameters were not measured on a scale, as this was not the initial question of the study. However, this finding was emerged during the study and it should be noted.

With regards to creatine safety, creatine was well-tolerated by all patients and no adverse events were reported. All patients remained in significant ketosis after the addition of creatine. No exacerbation of seizures, in terms of frequency or intensity, was noted in any of the 22 study patients during creatine supplementation. In addition, no pathological increases in Body Mass Index and no growth curve deviations were recorded during the period of the study. Finally, parameters of kidney function remained within normal ranges for age.

\section{Discussion}

The emerging finding of our study is that all patients who benefited from creatine had also benefited from the ketogenic diet. This gives us the ground to suppose that creatine acts in a way to augment the effects of the ketogenic diet. Nevertheless, it is unknown whether the creatine itself has anticonvulsant effects. The present study cannot not support such an assumption, because patients who had not benefited from the ketogenic diet did not benefit from creatine administration, too. At this time, although there is some experimental evidence in literature indicating antiepileptic actions of creatine, there is still no clinical evidence demonstrating such an effect [19-21].

Furthermore, the fact that our patients had already presented an improvement of seizure control after the initiation of ketogenic diet gives genesis to the question if this further reduction of seizures in these patients reflects the continuing effect of the diet over time. However, the significant improvement observed shortly after creatine supplementation, while these children were for more than 3 months in a stable condition, cannot not be exclusively attributed to the improving efficacy of ketogenic diet over time. In any case, a double -blind randomized clinical trial is the gold-standard to clarify creatine efficacy.

In parallel with seizure reduction an improvement in children's behavior was noted. Better seizure control and a concomitant reduction of anticonvulsant medication provide an obvious explanation. Although this may be true, there are also clinical data demonstrating independent beneficial effects of creatine on cognitive function [22-24]. Besides, previous studies have demonstrated improved behavior in children on ketogenic diet, while one prospective study has shown that behavioral improvement was uncorrelated with seizure reduction [25-27]. Based on data of the present study we can neither conclude that creatine itself facilitated behavior and cognitive functioning nor delineate the relative contributions of the ketogenic diet, decreased seizures and changes in medication.

Besides, the observation that 6 of the 22 patients experienced a further reduction in the number of seizures without affecting the level of ketosis raises the question whether the effects of the metabolic therapy can be independent of the level ketosis. If this is true, creatine supplementation could allow more liberal diet formulations.

While creatine seems to be a safe supplement, questions arise and allegations to the contrary exist from several food agencies and expert organizations, such as French Agency for Sanitary and Alimentary Security, Food and Drug Administration USA, American College of Sports Medicine [28-31]. A major point of controversy and concern is kidney function; few case reports have attributed renal dysfunction to creatine supplementation. However, this complication mainly concerns 
subjects with preexisting renal disease or predisposed to kidney diseases [32-33]. None of our patients during this study had renal dysfunction as we monitored kidney function regularly to avoid any adverse reactions during oral creatine supplementation.

Limitations of our study include the small number of participants, which affects generalizability of the findings, as well as the open study design, which does not permit to draw definite conclusions. Future double-blind clinical trials are needed to further explore the relationship between creatine supplementation and ketogenic diet and enhance the statistical power of the findings.

\section{Conclusion}

In conclusion, we provide evidence that creatine may have a positive effect on seizure control in children aged from 10months to 8 years old with normal kidney function and stable seizure frequency over a 3 -month time interval after being on the ketogenic diet for 8 to 24 months. The response to creatine administration seems to depend strongly on previous response to ketogenic diet.

Further questions arise concerning the optimal duration, dosage, as well as the types of epileptic syndromes which may benefit most from creatine supplementation. Despite issues needing further clarification, our study provides some evidence that adjuvant dietary creatine may have the potential to safely enhance the efficacy of ketogenic diet therapy.

\section{Acknowledgements}

None

\section{Conflicts of interest}

None

\section{Ethical standards}

Our study has been carried out in accordance with the Code of Ethics of the World Medical Association.

\section{Funding}

This research received no specific grant from any funding agency, commercial or not-for-profit sectors.

\section{References}

1. Russo A, Posar A, Conti S, Parmeggiani A (2015) Prognostic factors of drug-resistant epilepsy in childhood: An Italian study. Pediatr Int 57: 1143-1148.

2. Maudsley AA, Domenig C, Ramsay RE, Bowen BC (2010) Application of volumetric MR spectroscopic imaging for localization of neocortical epilepsy. Epilepsy Res 88 127-138. [Crossref]

3. Wasterlain GC, Thompson WK, Suchomelova L, Niquet J (2010) Brain energy metabolism during experimental neonatal seizures. Neurochem Res 35: 2193-2198.

4. Bough KJ, Wetherington J, Hassel B, Pare JF, Gawryluk JW, et al. (2006) Mitochondria biogenesis in the anticonvulsant mechanism of the ketogenic diet. Ann Neurol 60: 223235. [Crossref]

5. Reid CA, Mullen S, Kim TH, Petrou S (2014) Epilepsy, energy deficiency and new therapeutic approaches including diet. Pharmacol Ther 144: 192-201. [Crossref]

6. Kossoff EH, Hartman AL (2012) Ketogenic diets: new advances for metabolism-based therapies. Curr Opin Neurol 25: 173-178. [Crossref]

7. Rho JM, Stafstrom CE (2012) The ketogenic diet: what has science taught us? Epilepsy Res 100: 210-217. [Crossref]

8. Berger R, Middelanis J, Vaihinger HM, Mies G, Wilken B, et al. (2004) Creatine protects the immature brain from hypoxic-ischemic injury. $J$ Soc Gynecol Investig 11 : 9-15. [Crossref]
9. Adcock KH, Nedelcu J, Loenneker T, Martin E, Wallimann T, et al. (2002) Neuroprotection of creatine supplementation in neonatal rats with transient cerebral hypoxia-ischemia. Dev Neurosci 24: 382-388.

10. Sakellaris G, Kotsiou M, Tamiolaki M, Kalostos G, Tsapaki E, et al. (2006) Prevention of complications related to traumatic brain injury in children and adolescents with creatine administration: An open label randomized pilot study. J Trauma 61: 322-329.

11. Beal MF1 (2011) Neuroprotective effects of creatine. Amino Acids 40: 1305-1313. [Crossref]

12. Kim DW, Yeo SI, Ryu HJ, Kim JE, Song HK, et al. (2010) Effects of creatine and B-guanidinopropionic acid and alterations in creatine transporter and creatine kinases expression in acute seizure and chronic epilepsy models. BMC Neurosci 28: 111-141.

13. Mendes-Ribeiro JA, Soares R, Simões-Ribeiro F, Guimarães ML (1998) Reduction in temporal $\mathrm{N}$-acetylaspartate and creatine (or choline) ratio in temporal lobe epilepsy: does this $1 \mathrm{H}$-magnetic resonance spectroscopy finding mean poor seizure control? $J$ Neurol Neurosurg Psychiatry 65: 518-522.

14. Bough K (2008) Energy metabolism as part of the anticonvulsant mechanism of the ketogenic diet. Epilepsia 49 Suppl 8: 91-93. [Crossref]

15. Pan JW, Bebin EM, Chu WJ, Hetherington HP (1999) Ketosis and epilepsy: 31P spectroscopic imaging at 4.1 T. Epilepsia 40: 703-707. [Crossref]

16. Holtzman D, Meyers R, O'Gorman E, Khait I, Wallimann T, et al. (1997) In vivo brain phosphocreatine and ATP regulation in mice fed a creatine analog. Am J Physiol 272: C1567-1577.

17. Dechent P, Pouwels PJ, Wilken B, Hanefeld F, Frahm J (1999) Increase of total creatine in human brain after oral supplementation of creatine-monohydrate. Am J Physiol 277 R698-704. [Crossref]

18. Kwan P, Arzimanoglou A, Berg AT, Brodie MJ, Allen Hauser W, et al. (2010) Definition of drug resistant epilepsy: consensus proposal by the ad hoc Task Force of the ILAE Commission on Therapeutic Strategies. Epilepsia 51: 1069-1077.

19. Rambo LM, Ribeiro LR, Oliveira MS, Furian AF, Lima FD, et al. (2009) Additive anticonvulsant effects of creatine supplementation and physical exercise agains pentylenetetrazol-induced seizures. Neurochem Int 55: 333-340.

20. Royes LF, Fighera MR, Furian AF, Oliveira MS, Myskiw Jde C, et al. (2006) Effectiveness of creatine monohydrate on seizures and oxidative damage induced by methylmalonate. Pharmacol Biochem Behav 83: 136-144.

21. Holtzman D, Togliatti A, Khait I, Jensen F (1998) Creatine increases survival and suppresses seizures in the hypoxic immature rat. Pediatr Res 44: 410-414.

22. Owen L, Sunram-Lea SI (2011) Metabolic agents that enhance ATP can improve cognitive functioning: a review of the evidence for glucose, oxygen, pyruvate, creatine, and L-carnitine. Nutrients 3: 735-755.

23. Rawson ES, Venezia AC (2011) Use of creatine in the elderly and evidence for effects on cognitive function in young and old. Amino Acids 40: 1349-1362. [Crossref]

24. Li Z, Wang P, Yu Z, Cong Y, Sun H, et al. (2015) The effect of creatine and coenzyme q10 combination therapy on mild cognitive impairment in Parkinson's disease. Eur Neurol 73: 205-211.

25. Kinsman SL, Vining EP, Quaskey SA, Mellits D, Freeman JM. (1992) Efficacy of the ketogenic diet for intractable seizure disorders: review of 58 cases. Epilepsia 33: 1132 1136.

26. Nordli DR Jr, Kuroda MM, Carroll J, Koenigsberger DY, Hirsch LJ, et al. (2001) Experience with the ketogenic diet in infants. Pediatrics 108: 129-133. [Crossref]

27. Pulsifer MB, Gordon JM, Brandt J, Vining EP, Freeman JM (2001) Effects of ketogenic diet on development and behaviour: preliminary report of a prospective study. Dev Med Child Neurol 43: 301-306.

28. Jäger R, Purpura M, Shao A, Inoue T, Kreider RB (2011) Analysis of the efficacy, safety, and regulatory status of novel forms of creatine. Amino Acids 40: 1369-1383. [Crossref]

29. Bizzarini E, De Angelis L (2004) Is the use of oral creatine supplementation safe? $J$ Sports Med Phys Fitness 44: 411-416. [Crossref]

30. Gualano B, Artioli GG, Poortmans JR, Lancha Junior AH (2010) Exploring the therapeutic role of creatine supplementation. Amino Acids 38: 31-44. [Crossref]

31. Persky AM, Rawson ES (2007) Safety of creatine supplementation. Subcell Biochem 46: 275-289. 
Kalamitsou S (2019) The effect of creatine supplementation on seizure control in children under ketogenic diet: A pilot study

32. Francaux M, Poortmans JR (2006) Side effects of creatine supplementation in athletes. Int J Sports Physiol Perform 1: 311-323. [Crossref]
33. Juhn MS, Tarnopolsky M (1998) Potential side effects of oral creatine supplementation: a critical review. Clin J Sport Med 8: 298-304. [Crossref]

Copyright: $(2019$ Kalamitsou S. This is an open-access article distributed under the terms of the Creative Commons Attribution License, which permits unrestricted use, distribution, and reproduction in any medium, provided the original author and source are credited. 